\title{
Investigating the Influence of Using Peer Feedback on EFL Students' Speaking Achievement and Their Perceptions Towards Peer Feedback
}

\author{
Abiot Dagnew Chekol \\ Department of English Language and Literature, Injibara University, Injibara City, Ethiopia \\ Email address: \\ adagnaw03@gmail.com \\ To cite this article: \\ Abiot Dagnew Chekol. Investigating the Influence of Using Peer Feedback on EFL Students' Speaking Achievement and Their Perceptions \\ Towards Peer Feedback. Arabic Language, Literature \& Culture. Vol. 5, No. 3, 2020, pp. 23-34. doi: 10.11648/j.allc.20200503.11
}

Received: March 18, 2020; Accepted: June 30, 2020; Published: August 5, 2020

\begin{abstract}
This quasi-experimental study aimed at finding out the influence of using peer feedback on EFL students' speaking achievement and their perceptions towards peer feedback. One section of 39 grade eleven intact group students from nine sections at Injibara secondary school was taken as participants of the study. The data were collected using pre- and posttests, questionnaire and interview. For the data which were gathered using pre- and post-tests, t-test was employed as a statistical tool of analysis using paired samples t- test in SPSS. The questionnaire items, on the other hand, were analyzed quantitatively using frequency and percentage. Finally, the data obtained from the open-ended questionnaire item and interview items were analyzed qualitatively. The results of the study showed that, there was a statistically significant improvement in the overall speaking achievement of the students following the 12 peer feedback sessions in six weeks. Moreover, the students showed significant improvements mainly on the three aspects of speaking (grammar, fluency and vocabulary), but these students didn't show improvements on their pronunciation skills and their involvement in giving and receiving comments to and from their peers on their pronunciation skills was the least compared to the other aspects of speaking. Finally, the great majority i.e., 28 students $(85.2 \%)$ of the respondents developed positive perception towards the peer feedback they involved for six weeks and wanted it to be considered as part of their learning. In general, it was concluded that regardless of the quality of the comments from peers, no one denies that the more the students get involved in giving and incorporating comments to and from their peers, the better improvements they showed. Finally, it is recommended that learners have to be oriented to the 'new' roles of a learner which is not one of a receiver but of an active participant. Both teachers and learners have to accept the idea that effective and meaningful learning take place only when students actively contribute to the learning and negotiate constantly in terms of creating meaning.
\end{abstract}

Keywords: Peer, Feedback, Proficiency, Aspects, Perception

\section{Introduction}

\subsection{Background of the Study}

In Ethiopia English language has been considered as a central issue to education for many years. The role of English on the international level is a major factor that contributes to the increase in the importance of English in Ethiopia. Especially, nowadays due to globalization, English language has a great application in Ethiopia. Moreover, it is also used as a medium of instruction in secondary and tertiary levels of education. The learners can communicate with the foreign world comfortably; understand differences, exchange culture, express their opinions, intentions and viewpoints with the four English language skills in order to earn knowledge easily. As it was stated by Nunan (2003), the highest goal of learning English as a Foreign Language (EFL) is to communicate effectively [30].

Oral communication is the key to acquire the other language skills. It is vital for learners to have good classroom interaction. According to Bygate (1987), oral communication skill is cited as the single most important criterion in hiring professionals because most of the interview, group discussion, seminar presentation or some other form of oral 
communication need oral proficiency [10]. Bygate (1987) also argued that knowledge of highly sophisticated technical or professional skills will be useless if the employee does not know how to communicate with others about the information which results from the use and application of these technical and professional skills [10]. Students thus need specific oral communication skills if they are to be successful in their careers. This is supported by scholars such as Rivers (1981) who stated speaking is used twice as much as reading and writing in our communication [35].

In the early method of language teaching, the teacher was considered to be the sole source of knowledge. Among the various roles that a language teacher plays, giving feedback to learners' performance to correct their errors is one of the most significant. However, with the shift in method from Grammar Translation or Audio-lingual method to Communicative Language Teaching, teacher's role as a feedback provider was also changed. This is because the recent approaches and methods have emphasized a lot on learners' cognitive and their autonomy. With such a change, student-oriented techniques of error correction such as peer feedback have come up.

Peer feedback is an interactive process through which learners engage in dialogues associated with performance and standards [25]. They also claimed that peer feedback on drafts of students' assessment tasks is part of a new assessment culture which focuses on assessment for learning. Topping (2009), argued that peer feedback can potentially improve students' learning [40]. Peer feedback could also assist students to support in digging out their learning; recognizing strengths and weaknesses; targeting areas for remediation; sharing knowledge and developing metacognitive skills such as collaboration.

Peer feedback is a method that can help pupils to process their own and others' productions, as well as giving an opportunity to take responsibility for what they have learned and, therefore, influence their own learning [18]. Hyland and Hyland (2006), for instance, argued that peer feedback could positively influence pupils' autonomy and self-confidence, in that peer feedback requires active participation. Furthermore, peer feedback could be valuable for pupils' language development, such as classroom observation of pupils' oral production, but it may not be frequently used in the researcher's school for unknown reasons which need to be investigated.

\subsection{Statement of the Problem}

With the information revolution, globalization and other social and economic changes in the new Millennium, the importance of effective oral communication skills has increased. Though oral competency is vital for learners, the majority of the students (in the researcher's school) are not competent enough in English, especially in speaking.

Researchers in language learning have come up with different theories concerning how language is learnt. However, there is no consensus among them on how a second or foreign language is best learnt. Some scholars such as Williams and Burden (1997) viewed language as a social phenomenon and is learnt in social interactions. Others on the other hand, view language learning as an individual process [45].

For social interactionists, children are born into a social world, and learning occurs through interaction with other people. This interactionist view of language learning goes with Vygotsky's theory, Zone of Proximal Development /ZPD/. The theory is evident at every stage of human development when a person is moving from not knowing through a learning phase with the support of external agencies. It could be applied in learning situations by encouraging those who take part in the learning to interact. This view of learning emphasizes the role played by adults and competent peers in learning by sharing experience [43].

One area in which the social interactionist view can be applied in learning is through peer response in speaking. Collaborative learning theory encourages students to dig out their resources to complete tasks they could not do on their own, learning through dialogue and interaction with peers [18]. "The interactionsit perspective offered an important theoretical foundation for peer feedback by suggesting how opportunities to negotiate meaning through group work is a means of encouraging more effective acquisition of the language" [18].

According to the research conducted by Patri (2002), on the influence of peer feedback on self-and peer assessment of oral skills, his findings illustrated that peer feedback helped students develop judgmental skills to assess their peers that are comparable to those made by the teacher [31]. Therefore, the focus of his study was on the correlation between the self-and peer assessment with those made by the teacher's assessment. However, the central issue which is the speaking achievement of the students was not assessed by Patri and the current researcher wanted to investigate the influence of peer feedback on students' speaking achievement and their perceptions towards it.

Though many researches were conducted on the effect of peer feedback, the researcher didn't get many research works which were conducted on the influence of peer feedback on students' speaking achievement. This study, therefore, tried to investigate the influence of peer feedback in developing students' speaking achievement with particular reference to grade eleven students to fill the stated gaps.

\subsection{Research Questions}

This study has attempted to investigate the influence of peer feedback on EFL students' speaking achievement and their perceptions towards peer feedback. For this purpose the following research questions were formulated;

1. To what extent does peer feedback have an influence in developing students' speaking achievement?

2. What aspect(s) of speaking can be improved as a result of peer feedback?

3. What are the perceptions of students towards the peer feedback sessions on their speaking lessons? 


\section{Review of Related Literature}

\subsection{Collaboration in Language Learning}

According to Williams and Burden (1997: 4), "language is a social phenomenon and it is learnt when there is interaction among learners." The social interactionist view of learning emphasized the dynamic nature of the interplay between teachers, learners and tasks, and provides a view of learning arising from interactions with others [45]. From this, we can deduce that learning never takes place in isolation. This encourages the need for interactions among different groups in the learning process.

The fact that students are actively exchanging, debating and negotiating ideas within their groups increases students' interest in learning. More importantly, by engaging in discussion and taking responsibility for their learning, students are encouraged to become critical thinkers. If we are truly interested in preparing our students to be responsible citizens in an increasingly technologically advanced society, then our way of teaching our students must reflect this as well.

Likewise, students need to work in a collaborative or social setting in order to develop good communication skills. One way of developing speaking through collaboration is using peer feedback. Generally speaking, what all children seek is acceptance from their peers, working together is an opportunity to achieve this, so it is the teacher's job to make even the most reluctant participants see this by providing them with an environment in which they can speak without fear or embarrassment.

\subsection{Philosophy Behind Peer Feedback}

The idea of peer feedback is closely tied with learner autonomy as well as the say, "Tell us, we forget; Show us we remember; Involve us, we learn." Peer feedback is the technique which engages students to correct their own errors. It can also foster the development of skills needed to regulate their own learning and it places more responsibility for learning on the students [35].

\subsection{Feedback on EFL Students'Speaking}

In the context of teaching and learning language, there are a number of feedback definitions. Littlewood [24] and Lewis [23] were telling learners about their progress and showing them the errors in order to guide them to areas for improvement. Other definition of feedback is quoted by Berewot (2001: 17) presented that "feedback is the closing of a 'loop' in the learning process which serves to fix the learning result and make it permanently available.'[4]. Feedback is an expected and an important activity in a given performance. Particularly, in language teaching and learning it is used to facilitate the process. Ur (1996: 242) defined feedback in the context of teaching in general as "information that is given to the learner about his/ her performance of the learning task, usually with the objective of improving this performance.'[42]

Similarly Richards and Lockhart (1994: 188) stated
"Providing feedback to learners on their performance is an important aspect of teaching [34]. Feedback may serve not only to let learners know how well they have performed but also to increase motivation and build a supportive classroom climate."

It is widely recognized that feedback is an important part of the learning cycle, but according to literature both students and teachers frequently express their disappointment and frustration in relation to the conduct of the feedback process. Students may complain that feedback on assessment is unhelpful or unclear and sometimes even demoralizing. Additionally, students sometimes report that they are not given guidance as to how to use feedback to improve subsequent performance. Students also complain that the feedback given by their teachers is too late to be of any use or relevance at all.

According to Lewis (2002), feedback has to be given as soon as possible after the completion of the learning task. Students also need to see that the forwarded comments can be incorporated into subsequent performance and overall influence the quality of their learning in positive ways. Studies on the impact of feedback on student learning achievement indicate that feedback has the potential to have a significant effect on students' learning [23].

However, this potential is strongly related to the quality of the feedback, and unsurprisingly, Lewis (2002) noted that the most improvement in student learning takes place when students got information feedback about a task and how to do it more effectively and is clearly related to the learning goals [23].

By contrast, the impact of feedback on learning achievement is low when feedback focused on praise, rewards and punishment Littlewood (1981), also noted that feedback is more effective when it addresses achievable goals. He argued that the main purpose of feedback is to reduce the gap between current understandings and performance and goals [24].

Regarding the amount of feedback given to any task Crisp (2007), stated that it is not necessarily beneficial simply to increase the amount of feedback [19]. Instead it is nice to select different areas of the students work in relation to the criteria and provide quality feedback.

\subsection{Sources of Feedback on EFL Students'Speaking Achievement}

Lewis (2002: 15-23), stated that there are three sources of feedback. Namely: teacher feedback, self-evaluation (selfdirected feedback) and peer feedback [23].

(i) Teacher Feedback

Teachers have been the main sources of feedback both in oral and written languages in a range of topics [23]. This situation also occurs in speaking lesson and according to Harmer (2001) when students have completed an activity, it is vital that the teacher allows them to assess what they have done [17].

The question is when and how to give feedback in speaking lesson. It can be answered by considering carefully 
the effect of different approaches. In line with this, Harmer (2001) stated that when students are in the middle of the speaking task, overcorrection may inhibit them and take out the flow of the communication process [17]. Moreover, the teacher might not have enough time to provide comments for each student's oral presentation. Another problem of the teacher's feedback is that the comments written on the students' tasks are frequently written in a language that makes sense to teacher but which is not accessible to the students. Besides this, the feedback is a one way transmission from the teacher which will have little to do with the students' subsequent behaviors.

(ii) Self Evaluation (Self-directed Feedback)

Self-evaluation means the students correct and evaluate their own mistake. It may have an advantage of increasing students' independence as they are supposed to find their own mistakes. Then, by finding their own mistakes, the students are expected to remember what mistakes they have done so that they will not make the same mistakes in the subsequent speaking lesson.

(iii) Peer Feedback

Liu and Hansen (2005: 31) defined peer feedback as "the use of learners or peers as sources of information and interaction for one another in a way that the learners themselves take roles or responsibilities which are normally taken and done by teachers or trained tutors in commenting or criticizing their speaking." [25]. Wakabayashi (2013), discussed several different definitions of peer feedback [44]. All the different definitions emphasized learners as agents. Some focused on the negotiation process between learners or the learner as source of information. Wakabayashi (2013: 179), finally defined peer feedback as "a collaborative learning task by which learners acquire a revision procedures while taking on the dual rule of writer and reviewer." [44].

There are several different terms associated with peer related activities, which can broadly be divided into peer feedback and peer assessment. It is important to be able to distinguish between peer feedback and peer assessment, since the two terms, while having peer interaction as a central theme, having different goals and outcomes.

The main reason why I wanted to conduct a research on peer feedback in favor of peer assessment for this study was that marks would involve and there are also issues of reliability for giving marks by peers for peer assessment. As Liu and Carless (2006), argued there is a reluctance to use peer assessment due to reasons of reliability, and it is time consuming [25].

Lundstrom and Baker (2009), equated the term "peer review " with "peer editing", "peer response" and "peer evaluation" [26]. Whereas Mc Garrel (2010), decided to consider "peer feedback", "peer response" and "peer comment" as interchangeable [28]. Mc Garrel (2010: 72), argued that peer feedback was "supportive, constrictive but non evaluative criticism." [28]. consequently, while there are several different terms being used to refer to peer feedback, they seem to refer to an activity characterized by supportive and constructive interaction with peers.

Therefore, peer feedback is an activity where the learners are engaged in an actively collaborative task where they give and receive feedback and supportive, constructive and non evaluative comments from a person in a similar situation as the learners. Peer assessment, on the other hand, always include an evaluative element and is associated with grading and assessment. This paper however, focused exclusively on peer feedback. According to Freeman and Lewis (1998), good feedback is a two way process [15]. Verbal feedback is more likely to involve a two way process. When giving feedback, the one who gives feedback should try to stimulate a response and a continuing dialogue. These can alert students to the importance of considering and using feedback, and reflect on their performance and adjust their learning strategies.

\subsection{Speaking Skill}

Speaking is one of the four language skills (reading, writing, listening and speaking). It is the means through which learners can communicate with others to achieve certain goals or to express their opinions, intentions, hopes and viewpoints. In addition, speaking is the most frequently used language skill in almost any setting. This is supported by scholars such as Rivers (1981) who stated speaking is used twice as much as reading and writing in our communication [35].

According to Nunan (1989: 27) "Speaking can be classified to monologue and dialogue." [30]. The former focuses on giving uninterrupted oral presentation and the latter on interacting with other speakers. This research focuses on monologue because the researcher wants to observe each student's individual presentation so as to provide an opportunity for each participant to comment on each other's oral presentation and learn from their peers.

Developing speaking skill has a vital importance in EFL programs. Nunan [30] and Burkart and Sheppard [9] argued that success in learning a language is measured in terms of the ability to carry out a conversation in the target language. Besides the fact that speaking is a skill, which deserves attention like other skills, learners often need to be able to speak with confidence and carry out many of their basic transactions. They may make or lose their friends because of lack of speaking skill. It is a medium through which much language is learned.

Students need to be able to communicate confidently and appropriately with their peers and people from all walks of life: with those who are older or younger, with those in positions of power, with peers and family and with small and large groups. Students will, for example, learn how to interact productively with their peers, speak confidently in class discussions and listen strategically [12]. Learning English language involves developing both the ability to use the language effectively for a range of purposes and the ability to talk about the language being used. From this one can deduce that language is an integral part of learning, and oral language has a key role 
in classroom teaching and learning. It helps to encourage creativity, understanding, and imagination. It is a means of solving problems, sharing ideas and making decisions. Language builds friendship and enhances motivation through social interaction.

Oral presentation skills are increasingly important in a world where people are judged on their ability to present their ideas in a coherent and articulate way in a range of situations (schools, workplace, and society). This means, be fluent when expressing ideas or thoughts. Fluency means you can talk easily with native speakers- they easily understand you, and you easily understand them (ibid).

Students learn to speak by speaking [35]. However, the teaching of oral language skills was traditionally considered as the most difficult task; because in the past, written language was given more attention than speaking. Speaking a language is different for foreign language learners because effective oral communication requires the ability to use the language appropriately in social interactions.

Humans, being social animals, learn with and from others from the moment of birth. Much of this learning is informal, particularly in the years when we are not engaged in formal learning education. During formal learning, the teacher takes on an important role, particularly where the learning context is traditional.

Peer learning in which students learn with and from one another, may be less easily observed in my school context. Though learning is a social activity as it is stated in Vygotsky's theory in Zone of Proximal Development /ZPD/, requiring social interaction and collaboration.

However, in spite of the importance of the speaking skill, students in my school suffer weaknesses in their speaking performance. This may be due to the evaluation system that focuses mainly on reading, writing and listening or not giving enough time or opportunity for learners to practice speaking the language and learn from each other's comments since the teacher cannot provide comments' for every student's oral presentation due to shortage of time. Therefore, this research addressed the effect peer feedback has in developing learners' speaking achievement.

\subsection{Aspects of Speaking Skill}

Acquiring speaking skill is not easy for the students. They consider that speaking is the most difficult skill in language learning. Of course, teaching speaking is not as simple as the other skills of language learning. The main goal of teaching speaking itself is to make the students communicate in the target language.

Many aspects become the consideration of good speaking skill. The aspect of speaking determine as an indicator of speaking which is proposed by experts. Many scholars explain that there are generally, at least four components of speaking skill: grammar, vocabulary, pronunciation, comprehension and fluency. Thornbury (2005), for instance, stated that the planning of assessing speaking is the issue how to find the right balance between accuracy (vocabulary, grammar, pronunciation) and fluency [39]. Furthermore, Brumfit (1984) said speaking can more or less be divided in to two categories: fluency and accuracy [8]. Ur (1996) classified speaking scales including two aspects: namely fluency and accuracy (vocabulary, grammar and pronunciation) [42]. Finally, Aghdam and Farahani (2012), mentioned that anyone who wishes to speak in a foreign language must learn grammar, vocabulary and pronunciation [1]. The indicators of good speaking skill cover several sub skills: namely fluency vocabulary, grammar, pronunciation and comprehension. The students can be said good speaker if those components are fulfilled.

Speaking in a foreign language is a very demanding activity for all ages of learners. It is expected to share understanding with other people using a foreign language; one needs to pay attention to precise details of language. $\mathrm{He} /$ she needs to find the most appropriate words and also the correct grammar to convey meaning precisely and accurately. It is also very important to organize the discourse so that the listener understands what the speaker says. The basic elements of speaking skill which were stated by many scholars as mentioned above and the focus area of this research will be discussed as follows:

A. Accuracy: - According to Richards (1992: 31) accuracy concerns "the ability to produce grammatically correct sentences." In other words, accuracy in language means grammatical accuracy only [33]. Nevertheless, in Thornbury (2005), the term 'accuracy' means "doing without or with few errors on not only grammar but also vocabulary and pronunciation." He also sets clear criteria for assessment of accuracy:[39]. These are:

1. Grammar: Students use correct word order, tense, agreement, pluralism, articles, prepositions, etc. It is needed for students to arrange correct sentences and for students' ability to manipulate structure and to distinguish appropriate grammatical forms during their speech.

2. Vocabulary: One cannot effectively communicate or express his/her ideas both in oral and written form if they do not have sufficient vocabulary. Students have a range of vocabulary that corresponds to the syllabus and uses words the teacher has taught. According to Luoma (2004), using vocabulary adequately implies the ability to recognize and use words in the way that the speakers of the language use them. It implies using the common collocations of words and fixed phrases [27].

3. Pronunciation: students speak and most people understand. According to Dalton and Seidlhofer (1994), intelligibility is the most sensible goal of teaching pronunciation. Intelligibility means "being understood by a listener at a given time in a given situation" [13].

According to, Cornbleet and Cart (2001) include the following elements [11]:

Sound: these include consonants, vowels and silent letters.

Intonation: refers to "the pattern of pitch variation in a sentence" (Brinton, 2000: 62) [7]. Intonation is also called melody of speech (Roach, 1991) [36]. Speakers can change 
the pith of their voice by making it higher or lower in such a combination as rise-fall-rise or fall-rise-fall [21]. Intonation is a meaningful feature of speech which plays a central role in conveying attitudinal and emotional meanings.

Rhythm: it is created according to the position of stress within a single word or group of words. Stress is defined as the production of a syllable or word with more force than the surrounding syllables or words. One fundamental aspect in intelligible pronunciation that EFL learners should practice is placing stress on syllables because English is a 'stress timed' language [32]

B. Fluency:-fluency is also used as a criterion to measure one's speaking competence. Speaking fluently means being able to communicate one's idea without having to stop and think too much about what one is saying. Richards (1992: 141) defined fluency as "the feature which gives speech the qualities of being natural and normal."[33]. More specifically, Thornbury (2005) pointed out the criteria for assessing fluency. They are as follows [39]:

a. Lack of hesitation: students speak smoothly, at a natural speech. They do not hesitate (pause) long without too many "uh's", "um's" or "er's" and it is easy to follow what they are saying.

b. Length: students can put ideas together to form a message or argument. They can make not only the simplest sentence patterns but also complex ones.

c. Independence: students are able to express their ideas in a number of ways, keep talking and many more to keep the conversation going.

By taking the above scholars' justification of the basic aspects of speaking achievement, the researcher incorporated four basic components of speaking skill (grammar, vocabulary, pronunciation and fluency by categorizing them into two broad categories: accuracy (grammar, vocabulary and pronunciation) and fluency. The researcher also adopted assessment rubrics (criteria) of speaking score from the most recent EFL speaking tests to collect data on the aspects of speaking from the participants.

\section{Research Design and Methodology}

\subsection{Design of the Research}

Since the influence of peer feedback on students' speaking achievement needs to be identified through experimentation, the researcher used quasi-experimental design having one intact (naturally existing) group by way of simple random sampling system from the grade eleven sections which the researcher was assigned to teach. The main reason why the researcher chose quasi-experimental design from experimental design was that quasi-experimental design enabled the researcher to select naturally existing group than selecting the participants by randomization and forming artificial classrooms which might also be difficult to control extraneous variables. Furthermore, this design is manageable by limiting the interpretation of the cause and effect relationships.

\subsection{Participants of the Study}

The participants of the study were thirty-nine (39) students at the beginning of the school year though their number reduced to thirty-three (33) due to different reasons. Therefore, the researcher involved all the 33 students in this research. These students were taken from one section.

\subsection{Sampling Technique}

The researcher used simple random sampling technique by folding three small pieces of papers representing the three sections which the researcher was assigned to teach. Based on this, one section was selected as target of the study. Since the design of this study is quasi-experimental, all the students from this section were taken and included in the research without randomization.

\subsection{Data Gathering Tools}

The following instruments were employed for collecting data that could address the purpose of the study. These were: pre-test and post-test, questionnaire and interview.

\section{Findings and Discussions}

\subsection{Analysis of the Comments Given and Used During Peer Feedback Phase}

Table 1. Frequency of the comments given and used and the aspects of speaking students focused. $N=33$.

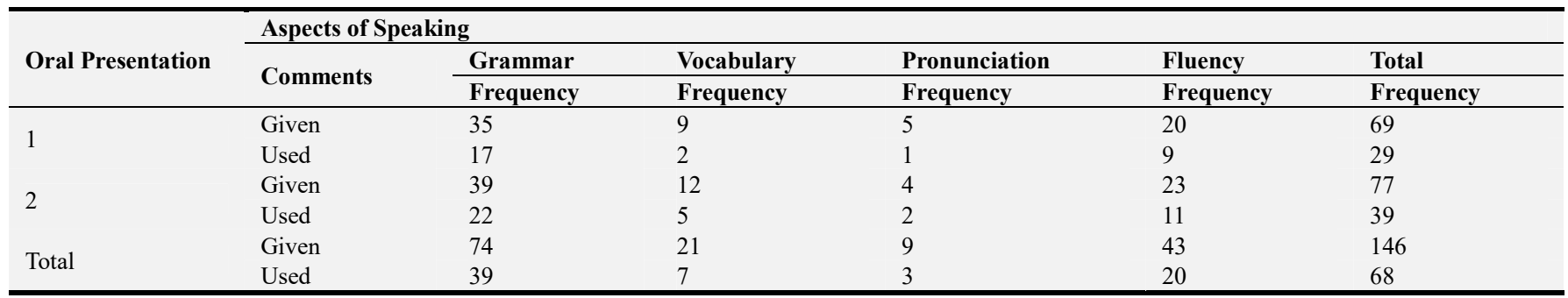

As indicated in the table, all the participants gave 74 comments on grammar, 43 comments on fluency, 21 comments on vocabulary and 9 comments on Pronunciation respectively during their first four oral presentations. The aspect of speaking which was given the highest comments in their first four presentations was grammatical accuracy 
followed by fluency and vocabulary. On the other hand, students exchanged fewest comments on their pronunciation (9 comments).

The above table also shows that students used 39 comments $(52.7 \%)$ of the total 74 comments given on grammar, 7 comments $(33.3 \%)$ of the total 21 comments given on vocabulary, 3 comments $(33 \%)$ of the total of 9 comments given on pronunciation, and 20 comments $(46.5 \%)$ of all the 43 comments given on fluency. In general, the students incorporated less than half $(46.5 \%)$ of all the comments given in all aspects of speaking.

\subsection{Analysis of the Students' Overall Speaking Achievement After the Intervention}

To test the above research question, the basic idea is simple. That means, if the treatment had no effect, the average difference between the measurements of the two tests is equal to zero. On the other hand, if the treatment did have an effect, the average difference is not zero. The average scores of the students before and after the intervention were analyzed using paired samples T- test in SPSS version 20.0 in the following table.

Table 2. Paired Samples T-test on the overall speaking achievement of students.

\begin{tabular}{|c|c|c|c|c|c|c|c|}
\hline Test scores & $\mathbf{N}$ & Mean & Std. Deviation & $\mathbf{T}$ & Df & Sig. (2-tailed) & Mean Difference \\
\hline Pre-test Score & 33 & 2.2083 & .60810 & \multirow{2}{*}{-8.154} & \multirow{2}{*}{32} & \multirow{2}{*}{.000} & \multirow{2}{*}{-.3258} \\
\hline Post-test score & 33 & 2.5341 & .64671 & & & & \\
\hline
\end{tabular}

At 0.05 level of significance

The result of the paired samples T-test from the above table indicates that there are differences between the means of pre-test and posttest. i.e. the mean speaking score of the students before the peer feedback was 2.20 , but this speaking mean score increased to 2.53 after involving the participants in peer feedback session. Therefore, the mean difference is .325 which is different from zero. This mean difference from the above table shows that peer feedback helped the students to improve their overall speaking achievement.

Moreover, depending on the above table $t$ (degree of freedom $)=\mathrm{t}$ - value, $\mathrm{p}=$ significance level. Therefore, $\mathrm{t}(32)=$ 8.154 , and Sig. (.000). Since the significance is .000 , which is less than $0.05(\mathrm{p}<0.05)$. This mean difference between the pre-test and post-test is statistically significant at 0.05 level of significance.

\subsection{Analysis of the Aspects of Speaking After the Intervention}

The aspects of speaking determine the overall speaking performance of the learners of which is proposed by many experts. Many aspects become the consideration of good speaking skill. The four aspects (components) of speaking which were mentioned as indicators of good speaking skill covered several sub-skills namely: grammar, pronunciation, vocabulary and fluency. To find out how the participants performed on these four aspects of speaking, the participants' speaking scores on each aspect of speaking before and after the intervention were analyzed using paired samples $\mathrm{T}$ - test to compare the means and to see the improvements after the peer feedback intervention in the table below.

Table 3. Paired Samples T-test on the aspects of speaking improved after the intervention.

\begin{tabular}{|c|c|c|c|c|c|c|c|c|}
\hline Speaking aspects & & Mean & $\mathbf{N}$ & SD & $\mathbf{T}$ & Df & Sig. (2-tailed) & Mean Diff. \\
\hline Grammar & $\begin{array}{l}\text { Pre-test (G1) } \\
\text { Post-test (G2) }\end{array}$ & $\begin{array}{l}2.7424 \\
3.3030\end{array}$ & $\begin{array}{l}33 \\
33\end{array}$ & $\begin{array}{l}.84891 \\
82858\end{array}$ & -6.946 & 32 & .000 & -.5606 \\
\hline Vocabulary & $\begin{array}{l}\text { Pre-test (Voc.1) } \\
\text { Post-test (Voc. } 2 \text { ) }\end{array}$ & $\begin{array}{l}2.3485 \\
2.5152\end{array}$ & $\begin{array}{l}33 \\
33\end{array}$ & $\begin{array}{l}.76531 \\
.67875\end{array}$ & -3.218 & 32 & .003 & -.1667 \\
\hline Pronunciation & $\begin{array}{l}\text { Pre-test (Pro. 1) } \\
\text { Post-test (Pro.2) }\end{array}$ & $\begin{array}{l}1.5606 \\
1.5909\end{array}$ & $\begin{array}{l}33 \\
33\end{array}$ & $\begin{array}{l}.55562 \\
.47524\end{array}$ & -.702 & 32 & .488 & -.0303 \\
\hline Fluency & $\begin{array}{l}\text { Pre-test (Flu.1) } \\
\text { Post-test (Flu.2) }\end{array}$ & $\begin{array}{l}2.1818 \\
2.7273\end{array}$ & $\begin{array}{l}33 \\
33\end{array}$ & $\begin{array}{l}.72692 \\
.84863\end{array}$ & -5.555 & 32 & .000 & -.5455 \\
\hline
\end{tabular}

At 0.05 level of significance

Based on the above table the aspects of speaking (grammar, vocabulary, pronunciation and fluency), $\mathrm{t}$ (degree of freedom $)=\mathrm{t}$ - value, $\mathrm{p}=$ significance level. Therefore, when we look at grammar, $\mathrm{t}(32)=-6.946$, and Sig. (.000). Since the significance is .000 , which is less than $0.05(\mathrm{p}<$ 0.05 ) for grammar, one can easily notice from the above table that there is a difference between the two means (Gr.1 and Gr.2). This result shows that there is a significant improvement on the students' grammatical accuracy.

On the other hand, when we look at another speaking aspect which is fluency from the above table, $\mathrm{t}(32)=-5.555$, and Sig. (.000). Since the significance is .000 , which is less than $0.05(p<0.05)$; we can see that there is a difference between the two means (Flu.1 and Flu.2). This implies that the participants showed significant improvements on their fluency too after the intervention. When we look at vocabulary from the above table $\mathrm{t}(32)=-3.218$, and Sig. (.003). This significance is less than $0.05(\mathrm{P}<0.05)$. This result shows that there is also an improvement after the intervention though there was no as such big mean difference like fluency and grammar which shows that students need to practice more to describe their ideas using adequacy of words and diction.

Finally, when we look at the last speaking aspect which is pronunciation, $\mathrm{t}(32)=-.702$, and Sig. (.488). The significance is .488 , which is not less than $0.05(\mathrm{p}>0.05)$. To say the 
treatment (peer feedback) has brought significant improvement in the participants' pronunciation skills the 'pvalue (.488) should be less than the alpha value $(0.05)$. Therefore, this finding from the above table shows that peer feedback didn't help students to improve their pronunciation skills.

\subsection{The Students'Perceptions on the Importance of Peer Feedback to Their Speaking Achievement}

This table shows the findings on the perceptions of students about the importance of peer feedback to their overall speaking achievement. The discussion on the importance of peer feedback is made based on this table.

Table 4. Students on the Importance of peer feedback $N=33$.

\begin{tabular}{|c|c|c|c|c|c|c|c|c|c|c|c|}
\hline \multirow{3}{*}{ № } & \multirow{3}{*}{ Items } & \multicolumn{10}{|c|}{ Response } \\
\hline & & \multicolumn{2}{|c|}{ SA (5) } & \multicolumn{2}{|l|}{ A (4) } & \multicolumn{2}{|c|}{ NI(3) } & \multicolumn{2}{|l|}{ D (2) } & \multicolumn{2}{|c|}{ SD (1) } \\
\hline & & Frq. & $\%$ & Frq. & $\%$ & Frq. & $\%$ & Frq. & $\%$ & Frq. & $\%$ \\
\hline 1 & $\begin{array}{l}\text { Comments from classmates helped me to improve my } \\
\text { speaking achievement. }\end{array}$ & 21 & 63.6 & 9 & 27.3 & 1 & 3 & 2 & 6.1 & - & - \\
\hline 2 & $\begin{array}{l}\text { Knowing what to do before peer feedback helped me a } \\
\text { lot in peer commenting. }\end{array}$ & 17 & 51.5 & 14 & 42.4 & 2 & 6.1 & - & & - & - \\
\hline 3 & $\begin{array}{l}\text { Classmates' comments were important as they were not } \\
\text { for marking. }\end{array}$ & 16 & 48.4 & 11 & 33.3 & 2 & 6.1 & 1 & 3.1 & 3 & 9.1 \\
\hline \multicolumn{2}{|r|}{ Total average frequency and percentage (Frq. and \%) } & 18 & 54.5 & 11 & 34.3 & 2 & 5.2 & 1 & 3 & 1 & 3 \\
\hline
\end{tabular}

In the above table, from a total of 33 students, 30 students $(90.9 \%)$ of the respondents agreed that comments from their classmates helped them to improve their overall speaking achievement. Only two students (6\%) of the students expressed their disagreement, and one student didn't comment in either way. Regarding the importance of training before the feedback session, 31 students $(93.9 \%)$ of the respondents stated that knowing what to do before the feedback session helped them a lot in peer commenting showing that training the students before involving them in the peer feedback session is very mandatory. Only 2 students $(6 \%)$ of the students didn't have any idea in either way.

Regarding the importance of their classmates' comments since they were not used for marking, 27 students (81.7\%) of the respondents expressed their agreement that peer comments were important as they were not used for marking which made them feel free to comment on their peers' speaking achievement and to incorporate the given comments in their subsequent speaking lessons. Only 2 students $(6 \%)$ of the total 33 students didn't comment in either ways, and 4 students $(12 \%)$ of the respondents expressed their disagreement.

\subsection{The Students' Perceptions on the Quality and Type of Comments Given and Used}

The quality, type and usefulness of the comments have a great influence in the development of the students' overall speaking achievement. In order to find out the students' perceptions on the quality, type and usefulness of the comments given and used, the participants' responses were analyzed as follows.

Table 5. Quality and type of comments given and used.

\begin{tabular}{|c|c|c|c|c|c|c|c|c|c|c|c|}
\hline \multirow{3}{*}{ № } & \multirow{3}{*}{ Items } & \multicolumn{10}{|c|}{ Response } \\
\hline & & \multicolumn{2}{|c|}{ SA (5) } & \multicolumn{2}{|l|}{ A (4) } & \multicolumn{2}{|c|}{ NI(3) } & \multicolumn{2}{|l|}{ D (2) } & \multicolumn{2}{|c|}{ SD (1) } \\
\hline & & Frq. & $\%$ & Frq. & $\%$ & Frq. & $\%$ & Frq. & $\%$ & Frq. & $\%$ \\
\hline 4 & $\begin{array}{l}\text { My classmates gave me useful comments on my } \\
\text { pronunciation during my presentation. }\end{array}$ & 7 & 21.2 & 4 & 12.1 & 6 & 18.2 & 10 & 30.3 & 6 & 18.2 \\
\hline 5 & $\begin{array}{l}\text { My classmates gave me useful comments on my fluency } \\
\text { during my presentation }\end{array}$ & 18 & 54.5 & 12 & 36.4 & 2 & 6.1 & - & - & 1 & 3 \\
\hline 6 & $\begin{array}{l}\text { My classmates gave me useful comments on the } \\
\text { adequacy of my vocabulary during oral presentation }\end{array}$ & 10 & 30.3 & 12 & 36.3 & 6 & 18.2 & 2 & 6.1 & 3 & 9.1 \\
\hline 7 & $\begin{array}{l}\text { My classmates gave me useful comments on my } \\
\text { grammatical accuracy during my presentation }\end{array}$ & 18 & 54.5 & 9 & 27.3 & 3 & 9.1 & 1 & 3 & 2 & 6.1 \\
\hline 8 & $\begin{array}{l}\text { I incorporated most of my classmates' comments in my } \\
\text { speaking presentation when I found them useful. }\end{array}$ & 23 & 69.7 & 7 & 21.2 & - & - & 2 & 6.1 & 1 & 3 \\
\hline 9 & $\begin{array}{l}\text { Since the students' comments were not misleading and } \\
\text { useless, I used their comments. }\end{array}$ & 26 & 78.8 & 4 & 12.1 & - & - & 2 & 6.1 & 1 & 3 \\
\hline \multicolumn{2}{|r|}{ Total average frequency and percentage (Frq. and \%) } & 17 & 51.5 & 8 & 24.3 & 3 & 9.1 & 3 & 9.1 & 2 & 6 \\
\hline
\end{tabular}

From the above table, regarding the students' ability to comment on their pronunciation, 16 students $(48.5 \%)$ of the respondents expressed their disagreement that their peers' comments helped them to improve their pronunciation. Moreover, 6 students (18.2\%) of the respondents abstained from giving comments on either way showing that they were not sure of the usefulness of their peers' comments to improve their pronunciation. In general, 22 students $(66.6 \%)$ of the respondents had doubts on the quality and usefulness of their peers' comments on their pronunciation which led them not to incorporate the comments into their subsequent oral presentations. Only 11 students $(33.3 \%)$ of the respondents expressed their agreement on the usefulness of their classmates' comments on their pronunciation. 
Concerning the students' ability to comment on their fluency, 30 students $(90.9 \%)$ of the respondents showed their agreement that their classmates gave them useful comments on the fluency of their oral presentations. Only 2 students $(6 \%)$ of the respondents abstained from giving comments on either way, and finally one student expressed his/ her disagreement.

Regarding the students' ability to comment on the adequacy of their vocabulary, 22 respondents $(66.6 \%)$ of the respondents expressed their agreement on the quality and usefulness of their peers' comments, 5 students $(15.06 \%)$ of the respondents expressed their disagreement, and the rest of the respondents i.e. 6 students $(18.2 \%)$ of the respondents didn't comment on either way.

With respect to the students' ability to comment on their grammatical accuracy, most of the students i.e. 27 students $(81.8 \%)$ of the respondents showed their agreement that their classmates gave them useful comments on their grammatical accuracy of their oral presentations. 3 students $(9.1 \%)$ of the respondents expressed their disagreement, and the remaining 3 students $(9.1 \%)$ of the respondents abstained from giving comments either way.

With respect to how the students incorporated their peers' comments, almost all of the students i.e. 30 students (90.9\%) of the respondents expressed their agreement that they incorporated most of their classmates' comments in their subsequent oral presentations when they found them useful. Only 3 students $(9.1 \%)$ of the respondents disagreed with the idea that they incorporated most of their peers' comments in their subsequent oral presentations. The students were also asked to comment on whether their classmates' comments were misleading and useless or not. From their responses, almost all of the students i.e. 30 students $(90.9 \%)$ of the respondents agreed to the belief that their classmates' comments were not misleading and useless, and therefore they used their peers comments in their next oral presentations. Only 3 students $(9.1 \%)$ of the respondents perceived that their classmates' comments were misleading and useless and they didn't use their comments at all.

\subsection{The Students' Perceptions on the Affective Benefits of Peer Feedback}

Students' perceptions on the affective benefits of peer feedback have a strong impact on their overall speaking achievement. And as a result, an analysis was made on their feelings after gathering data from the participants, and the data is presented as follows in the following table.

Table 6. Affective benefits of peer feedback. $N=33$.

\begin{tabular}{|c|c|c|c|c|c|c|c|c|c|c|c|}
\hline \multirow{3}{*}{ № } & \multirow{3}{*}{ Items } & \multicolumn{10}{|c|}{ Response } \\
\hline & & \multicolumn{2}{|c|}{ SA (5) } & \multicolumn{2}{|l|}{ A (4) } & \multicolumn{2}{|c|}{ NI (3) } & \multicolumn{2}{|c|}{ D (2) } & \multicolumn{2}{|c|}{ SD (1) } \\
\hline & & Frq. & $\%$ & Frq. & $\%$ & Frq. & $\%$ & Frq. & $\%$ & Frq. & $\%$ \\
\hline 10 & $\begin{array}{l}\text { Exchanging comments with my classmates made me be more } \\
\text { active during speaking activities. }\end{array}$ & 16 & 48.5 & 13 & 39.5 & 2 & 6 & 2 & 6 & - & - \\
\hline 11 & $\begin{array}{l}\text { Exchanging comments with my classmates during oral } \\
\text { presentation increased my confidence in speaking. }\end{array}$ & 23 & 69.7 & 7 & 21.3 & 1 & 3 & 2 & 6 & - & - \\
\hline 12 & $\begin{array}{l}\text { Exchanging comments helped me to reduce the fear I had during } \\
\text { oral presentation. }\end{array}$ & 17 & 51.5 & 12 & 36.4 & 1 & 3 & 3 & 9.1 & - & - \\
\hline 13 & Exchanging comments were interesting. & 23 & 69.7 & 8 & 24.3 & - & & 2 & 6 & - & - \\
\hline \multicolumn{2}{|c|}{ Total average frequency and percentage (Frq. and \%) } & 20 & 60.6 & 10 & 30.4 & 1 & 3 & 2 & 6 & - & - \\
\hline
\end{tabular}

From the above table, 29 students $(88 \%)$ of the respondents expressed their agreement that exchanging comments with their classmates made them be more active during their oral presentation. The remaining two students $(6 \%)$ of the respondents disagreed with the idea, and finally two students abstained from giving comments either way. With respect to the students' understanding of peer feedback in developing their confidence, almost all of the respondents i.e. 30 students $(91 \%)$ of the respondents expressed their agreement that exchanging comments with their classmates during their oral presentation increased their confidence in speaking. Two students expressed their disagreement and one student remained undecided without giving his/ her comment either way.

When we look at the average frequency and percentage of the four items from the above table, the great majority i.e, 30 students $(91 \%)$ of the respondents understood the affective benefits of peer feedback in making learners be active and confident by reducing their frustration during their oral presentation. This implies that the students developed a positive attitude towards peer feedback in their speaking lessons. This is because peer feedback is an interactive process which made learners take responsibilities to their own learning and motivate them to be active participants within their one to five (1 to 5) group arrangement besides improving their overall speaking achievement. Only two students disagreed with this idea and one didn't say either way.

The last item of the questionnaire is open-ended item. The researcher read all the responses of the students on the openended item, and from the responses of the participants' written responses, almost all the students showed a strong interest and a positive attitude towards the peer feedback they exchanged in their oral presentation. Some of the comments written by the students were: "if this continues throughout the year just we become good speakers, confident and improve our pronunciation; it helps me to remember many words and helps me communicate in English with other people without fear; when I speak in front of the people, I was afraid a lot but now I improve, so this is important for my future life. I like the comments from my friends, it is very important in grammar and fluency to increase my confidence 
of speaking and the like..." one student commented that "my friends gave me useful comments on grammar but I didn't get useful comments mainly on my pronunciation". He /she added that in general, the comments were useful for improving my next speaking. Another student also described his/her idea that "there are more comments on grammar and fluency rather than pronunciation". He/she also added that the comments he/she received from his/her classmates were generally important, and this student also mentioned that "these comments were important to me because they helped me to know my mistakes for the next oral presentation and increased my confidence".

\subsection{Discussion}

The first research question was aimed at finding out the extent to which peer feedback has an influence on developing the students' overall speaking achievement. The findings of the data obtained from pre- and post-tests which were analyzed using paired samples T- test as it is stated in Table 2 shows that there was a statistically significant improvement in the overall speaking achievement following the twelve peer feedback and speaking sessions for six weeks since $\mathrm{t}(32)=-8.154$, and Sig. (.000), and this significance which is .000 , is less than $0.05(\mathrm{p}<0.05)$. Moreover, the mean difference between the pre- and post-test analysis from Table 2 is -.325 which is different from zero. This mean difference was the result of the different speaking achievements of the participants before and after the peer feedback session. This mean difference is negative which implies that the post test score is greater than the pre-test score since mean difference is computed by subtracting post-test mean from the pre-test mean. This is also verified by the questionnaire data when asked if comments from classmates helped them to improve their speaking achievement. 30 students $(90.9 \%)$ of the respondents agreed that comments from their classmates helped them to improve their overall speaking achievement and they perceived that peer feedback has a role in developing their overall speaking achievement (See Table 6). The interview data also showed that all the five students stated that exchanging comments on their oral presentations were important to improve their overall speaking achievement and they wanted it to keep going throughout the year and to be considered as a part of their learning process. The finding of this study is in line with the findings of the study conducted by Axelsson (2014) on peer feedback and language development for English L2 learners in Swedish context [3]. The results in her study indicated that peer feedback could have beneficial effects for pupils' language development though few students mistrust their peers' ability to give comments due to lack of sufficient training.

The second research question was aimed at examining the aspect(s) of speaking improved as a result of peer feedback intervention. After analyzing the data which were obtained from pre-test and post-test to see the aspects of speaking developed as a result of peer feedback using paired samples T-test as it is stated in Table 4, the findings showed that the students brought significant improvements mainly on their grammar (mean difference -.560), fluency (mean difference .545 ) and vocabulary (mean difference -.166) skills respectively. This mean differences between the pre- and post-tests showed that there was a significant improvement in these aspects of speaking due to the peer feedback intervention. The reason was that as it is stated in Table 1 the participants exchanged and incorporated many comments mainly on their grammar and fluency respectively than on their vocabulary and pronunciation. From the above justification, one can conclude that the more the students involve in giving and incorporating their peers' comments, the better improvements they will show in developing the components (aspects) of speaking. This finding was consistent with the finding of the study conducted by Jones and Breg' (1999), by stating the students' active involvement in giving feedback provides them a voice in scaffolding and constructing their own knowledge and eventually improving their language by sharing what they think [6].

Though the students' exchanged few comments on their vocabulary skills compared to the frequency of the grammar and fluency comments given and incorporated on their first four oral presentations as it is stated in Table 1, they showed improvements in their vocabulary skills after the intervention. This is because students can improve their adequacy of their vocabulary if they practice a lot. This finding goes along with Arju's (2011) research finding on Bangladeshi secondary school students by stating students of English as a Foreign Language are lagging behind because of having an inadequate stock of vocabulary. However, a regular practice in the classroom may enhance the learners' vocabulary knowledge [2].

In addition, the above finding also goes along with the finding obtained from the students' questionnaire when asked if their peers' comments were important to improve their pronunciation skills; 22 students $(66.6 \%)$ of the respondents had doubts on the quality and usefulness of their peers' comments and disagreed with the idea that their classmates gave them useful comments during their oral presentation to improve their pronunciation skills. This led them not to incorporate their peers' comments into their subsequent oral presentation.

The third research question was aimed at assessing the perceptions of the students towards the practice of peer feedback in speaking lessons. From the very beginning of this study, many students were not interested in involving in peer feedback because they thought that it takes their time than developing their speaking achievement, but after the researcher explained the purpose of peer feedback, its role in developing their speaking achievement and giving sufficient training on how to involve in peer feedback on their oral presentation based on the evaluation criteria and some guidelines, their perceptions were changed completely. This idea goes along with Falchikov's (2005) research finding, who stated students' perceptions towards peer feedback were less than positive at the initial stage, but their attitude changed and their involvement in peer feedback improved as the students became more experienced in giving and 
receiving feedback [14].

\section{Conclusions}

Based on the findings of the study, the following conclusions were drawn.

a) There is a strong relationship between the amount of peer feedback given and the improvement of their aspects of speaking. This means students exchanged a lot of comments on their grammatical accuracy, fluency and vocabulary respectively which results in the improvement of these speaking aspects. On the contrary, students exchanged the least comments mainly on their pronunciation which made them not to improve this speaking aspect after the intervention. Moreover, if the students lack good knowledge of the topic like pronunciation, which made them face difficulty of identifying their peers' errors so as to give appropriate feedback, they will not improve their language skills.

b) Peer feedback was found to be helpful mainly for improving grammar, fluency and vocabulary. The students faced difficulty of giving comments on their peers' pronunciation in particular. On the contrary, this is because from the researcher's observation and from the responses of the students, it was clearly observed that students faced problem of providing feedback to their peers because they couldn't identify their peers' pronunciation errors. This implies that the students' level of understanding to provide sufficient feedback on pronunciation errors were low which made them show no improvements on it.

c) The participants showed significant improvements in their overall speaking achievements. In general, regardless of the accuracy and scope of the comments, which were given by their peers, no one denies the importance of peer feedback in making learners have good classroom interaction, in making the lesson student-centered, in developing autonomous learning, in reducing their fear during their oral presentation and in teaching speaking in general besides the overall improvement of the speaking achievement.

d) From the responses of the students' questionnaire and interview, the great majority of the participants developed a positive attitude towards the practice of peer feedback and wanted it to continue throughout the year. On the other hand, they said that they used the comments selectively by focusing on the comments mentioned in many of the group members and the common ones because they thought that some of the comments were incorrect and didn't reflect their errors.

\section{References}

[1] Aghdam, Z. S., and Farahani, A. (2012). Speaking as an Indicator of General Proficiency in Placement Test. University of Tehran, Iran.
[2] Arju, S. (2011). A Study on EFL Vocabulary Acquisition Needs and Classroom Practice: Bangladeshi Context: Journal of English, 6 p. 51-67.

[3] Axelsson, S. (2014). Peer Feedback and Language Development for English L2 Learners in a Swedish Context. Journal of Second Language Writing. 11 (07).

[4] Berewot, J. (2001). The Effectiveness of Teacher's Written Feedback in Developing Grammatical Mastery. Yogyakarta: Sanata Dharma University.

[5] Boud, D. (1994). Implementing Student Self Assessment. HERDSA Green Guide. Second Edition. Sydney: HERDSA.

[6] Breg, E. (1999). "The effects of Trained Peer Response on ESL Students' Revision Types Writing Quality." Journal of Second Language Writing, 8 (3): 215-241.

[7] Brinton, J. L. (2000). The Structure of Modern English: A Linguistic Introduction. Amsterdam: John Benjamin's Publishing Company.

[8] Brumfit, C. (1984). Communication Methodology in Language Teaching. Cambridge: Cambridge University Press.

[9] Burkart, G. and Sheppard, K. (2004). Content ESL across the USA: A Training Packet. Descriptive Study of Content-ESL Practices. National Clearinghouse for English Language Acquisition.

[10] Bygate, M. (1987). Speaking. Oxford: Oxford University Press.

[11] Cornbleet, S. and Carter, R. (2001). The Language of Speech and Writing. London: Routledge.

[12] Cotter, Ch. (2007). Speaking Well-Four Steps to Improve Your ESL/EFL Students' Speaking Ability.

[13] Dalton, C. and Seidlhofer, B. (1994). Pronunciation. Oxford: OUP.

[14] Falchikov, N. (2005). Improving Assessment through Student Involvement. London and London and New york: Rout ledge Falmer.

[15] Freeman, R. and Lewis, R. (1998). Planning and Implementing Assessment. London: Kogan Page.

[16] Hansen, J. G. and Liu, J. (2005). Peer Response in Second Language Classrooms. Ann Arbor, MI: University of Michigan.

[17] Harmer, J. (2001). The practice of English Language Teaching. Edinburgh: Pearson Education Limited.

[18] Hyland, k. and Hyland, F. (2006). Feedback on Second Language Students writing: Language Teaching Techniques, 39: 83-101.

[19] Joyce, H. and Burns, A. (1999). Focus on Speaking. Sydney: National Center for English Language Teaching and Research.

[20] Juwah, C. (2004). Enhancing Student Learning Through Effective Formative Feedback. York, England: Higher Education Academy (Generic centre).

[21] Kenworthy, J. (1987). Teaching English Pronunciation. London: Longman.

[22] Koul, L. (1984). Methodology of Educational Research (2 ${ }^{\text {nd }}$ ed.), Delhi: Vikas Publishing Ltd. 
[23] Lewis, M. (2002). Giving Feedback in Language Classes. The University of Auckland: SEAMO Regional Language Centre.

[24] Littlewood, W. (1981). Communicative Language Teaching: An Introduction. Cambridge: Cambridge University Press.

[25] Liu, N., and Carles, D. (2006). Peer Feedback the Learning Element of Peer Assessment Teaching in Higher Education, 11 (3).

[26] Lundstrom, k. \& Baker, W. (2009). To Give is Better than to Receive: The Benefits of Peer Review to the Reviewer's own Writing. Journal of Second language writing, 18, 30-43.

[27] Luoma, S. (2004). Assessing Speaking. Cambridge: Cambridge University Press.

[28] Mc Garrel, H. (2010). Native and Non-native English Speaking Student Teachers Engage in Peer Feedback. The Canadian Journal of applied Linguistics. 13 (1), 71.

[29] Min, H. (2006). The Effects of Trained Peer Review on EFL Students' Revision and Writing Quality. Journal of Second Language Writing, 15, 118-141.

[30] Nunan, D. (1989). Designing Tasks for the Communicative Classroom. New York: Cambridge University Press.

[31] Patri, M. (2002). The Influence of Peer Feedback on Self and Peer Assessment of Oral Skills. City University of Hong kong. 19 (2) 109-131.

[32] Pennington, M. C. and J. C. Richards (1986). 'Pronunciation Revisited': TESOL Quarterly, 22/2, 207-221.

[33] Richards, J. (1992). Thinking, Problem Solving, Cognition $\left(2^{\text {nd }}\right.$ ed.). A Series of Books in Psychology. New York: Times Books.

[34] Richards, J. C. and Lockhart, C. (1994). Reflective Teaching in Second Language Classrooms. Cambridge: Cambridge University Press.
[35] Rivers W. (1981). Teaching Foreign Language Skills. University of Chicago Press.

[36] Roach, P. (1991). English Phonetics and Phonology. Cambridge: Cup, $2^{\text {nd }}$ ed.

[37] Sitthiworachart, J. and Joy, M. (2003). Web-based Peer Assessment in learning Computer Programming. Department of Computer Science, University Warwick.

[38] Skolverket, (2011). Curriculum for the Upper Secondary School. Syllabus for English.

[39] Thornbury, S. (2005). How to Teach Speaking. London: Longman.

[40] Topping, K. J. (2009). Peer Assessment. Theory into Practice, $48(1), 20-27$.

[41] Tsui, A. M. B. and Ng, M. (2000). "Do Secondary L2 Writers Benefit from Peer Comments?" Journal of Second Language Writing. 9 (2): 147-170.

[42] Ur, P. (1996). A Course in Language Teaching. Practice and Theory. Cambridge: Cambridge University Press.

[43] Vygotsky, L. S. (1978). Mind in Society: The Development of Higher Psychological Processes. Cambridge. Harvard University Press.

[44] Wakabayashi (2013). The Effects of the Peer Feedback Process on Reviewers' English Language Teaching, 6 (9), 177-192.

[45] Williams, M. and Burden, R. L. (1997). Psychology for Language Teachers: a Social Constructivist Approach. Cambridge: Cambridge University Press.

[46] Yang, M, Badger, R. and Yu, z. (2006). A Comparative Study of Peer and Teacher Feedback in a Chinese EFL Writing Class. Journal of $2^{\text {nd }}$ Language Writing. 